\title{
PENERAPAN AUDIT BASED RISK PADA PIUTANG MURABAHAH (Studi pada Bank Muamalat Malang)
}

\author{
Dimas Mahardika Palupi*, Eris Tri Kurniawati \\ Program Studi Akuntansi Fakultas Ekonomi dan Bisnis \\ Universitas Muhammadiyah Malang \\ Jl. Raya Tlogomas No. 246 Malang \\ *Corresponding author: dimaspalpo8@gmail.com
}

\begin{abstract}
This study aims to analyze the implementation of audit-based risk on murabahah receivables in accordance with Indonesian bank regulations at Bank Muamalat Malang. The type of this research is descriptive qualitative with the technique used is an interview, observation, and documentation. Researchers used six risk control elements in accordance with control objectives. The result of the analysis at Bank Muamalat Malang shows that risk control is quite good. the implementation of effective risk management is good enough. The scope of risk management performed by the Bank is good enough. The risk rating for prioritizing the mitigation is also good. Practice with the principles of sharia and not contrary to the MUI fatwa is good. Implementation of risk management in Syariah business unit does not exist because in Bank Muamalat Malang there is no unit of sharia business. The rules of delivery on a quarterly basis to BI have also been disputed.
\end{abstract}

Keywords: audit based risk, murabahah receivables

\section{PENDAHULUAN}

Perbankan harus memiliki pengawasan yang efektif terkait operasi perusaan yang diatur oleh Peraturan Bank Indonesia nomor 13/23/PBI/2011 mengenai pelaksanaan manajemen risiko pada bank dan surat edaran terkait dengan pelaporan risiko perusahaan pada OJK. Keamanan perbankan juga sangat dipengaruhi oleh kepekaan auditor dalam penangkapan juga tindak lanjut mengenai risiko dan eksposure yang akan terjadi pada perusahaan.

Pada studi yang dilakukan oleh COSO (Commite of Sponsoring Organization of the Treadway Commission), mengenai pengendalian internal dalam kerangka kerja terintegrasi. Penentuan risiko oleh auditor internal dianalisis

Diterima 28 Sep 2018

Direviu 2 Okt 2018

Direvisi 31 Okt 2018

Diterima 2 Nov 2018

Artikel ini tersedia di website :

http://ejournal.umm. ac.id/index.php/jaa melalui tujuan yang dihubungkan pada tingkat-tingkat berbeda dan konsisten, yang kemudian diidentifikasi dan dianalisis risiko yang relevan untuk mencapai tujuan perusahaan yang kemudian terbentuknya dasar cara pengendalian risiko (Sawyer dkk., 2005).

Adanya pengawasan risiko yang dilakukan oleh pihak Manajemen melalui Auditor Internal perusahaan mampu bertahan untuk bersaing di dalam bisnis yang sama. Bank memiliki sistem yang sangat ketat dalam pengawasan karena jasa yang diberikan berdampak langsung kepada nasabah dan integritas Bank apabila terjadi kesalahan yang berlarut-larut dan tidak dievaluasi, sehingga akan berdampak pada perusahaan itu sendiri. Pada studi yang dilakukan oleh Wandayanik (2015) tentang pentingnya pengendalian internal pada Bank BNI 
syariah kantor cabang pembantu Mojokerto dengan menggunakan prosedur $5 \mathrm{C}$ (character, capital, capacity, collateral, dan condition of economic) yang telah di tetapkan oleh Bank pusat guna menanggulangi risiko.

Studi yang dilakukan oleh Arifa \& Farida (2015) tentang pentingnya pengendalian internal maka dibentuknya satuan kerja audit internal (SKAI) untuk melakukan pengawasan di Bank juga dibuat sistem pengendalian internal (SPI) yang efektif guna melindungi dan menjaga aktifitas bisnis dari Bank. Penelitian ini dilakukan guna mengetahui praktik pada akad murabahah dan juga untuk mengetahui risiko apa saja yang terkait dengan akad murabahah serta untuk mengetahui bagaimana cara menangani permasalahan yang dihadapi. Berlandaskan pada peraturan yang berlaku di Indonesia.

Antonio (2005) mendasarkan pembiayaan pada penggunaannya dapat dibagi menjadi 2 (dua). Pembiyaan Produktif adalah pembiayaan yang diperuntukkan memenuhi kebutuhan produksi dalam arti luas dan pembiyaan Konsumtif adalah pembiyaan yang ditujukan untuk kebutuhan konsumsi, yang akan habis untuk memenuhi kebuthan.

Pembiayaan produktif yang berdasar penggunaannya juga di bagi menjadi 2 (dua). Pembiayaan Modal Kerja adalah pembiayaan untuk memenuhi kebutuhan peningkatan produksi, baik secara kuantitatif atau kualitatif dan Pembiayaan Investasi adalah pembiayaan yang dipergunakan untuk memenuhi kebutuhan barang-barang modal (capital goods) serta fasilitas-fasilitas yang berkaitan dengan hal tersebut. Murabahah sendiri adalah akad jual beli suatu barang dengan menegaskan harga belinya oleh penjual kepada pembeli dan pembeli membayarnya dengan harga yang lebih sebagai laba.

Produk Bank Muamalat yang menggunakan akad murabahah ada dua yaitu pembiayaan kredit perumahan rakyat (KPR) dan pembiayaan Multiguna seperti renovasi rumah, kepemilikan sepeda, pernikahan dan alat rumah tangga. Nonperforming Financing (NPF) atau pembiayaan bermaslah naik $0.2 \%$ dari 4,56\% menjadi 4,76\% pada kuarter 1 tahun 2018. Adanaya kenaikan NPF pada kuarter 1 yang mendekati batas NPF BI yaitu 5\% dan apabila sudah 5\% atau melampaui maka bank yang bersangkutan tidak boleh melakukan pembiayaan kepada nasabah, yang akan merugikan investor, bank itu sendiri dan investor lain yang menyimpan uangnya di Bank Muamalat Malang.

Peraturan Bank nomer 13/23/PBI/2011 mengatur terkait manajemen risiko dengan kewajiban Bank menerapkan manajemen risiko secara efektif, cakupan dari manajemen risiko, peringkat risiko, pelaksanaan yang tidak bertentangan dengan prinsip syariah, penerapan manajemen risiko pada unit usaha syariah dan penyampaian risiko secara triwulan kepada BI. Berdasar pada uraian di atas, maka tujuan dalam penelitian ini adalah menganalisis penerapan audit based risk pada piutang murabahah pada Bank Muamalat Malang.

\section{METODE}

Jenis penelitian yang dilakukan yaitu deskriptif kualitatif dengan pendekatan studi kasus pada Bank Muamalat Malang. Data yang digunakan berupa struktur organisasi perusahaan serta pembagian tugas dan wewenang, bagan alur pengajuan Akad Murabahah, Bagan alur dimulainya Akad Murabahah, bagan alur pelunasan oleh nasabah pada Akad Murabahah, bagan alur jika ada permasalahan dari nasabah, dan sejarah berdirinya Bank Muamalat. Data diperoleh melalui wawancara, observasi dan dokumentasi. Adapun teknik analisis yang digunakan yaitu mengidentifikasi enam komponen Manajemen 
Risiko berdasarkan Peraturan Bank Indonesia No 13/23/PBI/2011 pada Bank Muamalat Malang yang meliputi penerapan manajemen risiko oleh Bank secara efektif, cakupan dari manajemen risiko, peringkat risiko, pelaksanaan yang tidak bertentangan dengan prinsip syariah, penerapan manajemen risiko pada unit usaha syariah, penyampaian risiko secara triwulan kepada BI.

\section{HASIL DAN PEMBAHASAN}

PT Bank Muamalat Indonesia Tbk ("Bank Muamalat Indonesia”) memulai perjalanan bisnisnya sebagai Bank Syariah pertama di Indonesia pada 1 November 1991 atau 24 Rabi'us Tsani 1412 H. Pendirian Bank Muamalat Indonesia digagas oleh Majelis Ulama Indonesia (MUI), Ikatan Cendekiawan Muslim Indonesia (ICMI) dan pengusaha muslim yang kemudian mendapat dukungan dari Pemerintah Republik Indonesia. Sejak resmi beroperasi pada 1 Mei 1992 atau 27 Syawal 1412 H, Bank Muamalat Indonesia terus berinovasi dan mengeluarkan produk-produk keuangan syariah seperti Asuransi Syariah (Asuransi Takaful), Dana Pensiun Lembaga Keuangan Muamalat (DPLK Muamalat) dan multifinance syariah (Al-Ijarah Indonesia Finance) yang seluruhnya menjadi terobosan di Indonesia. Selain itu produk Bank yaitu Shar-e yang diluncurkan pada tahun 2004 juga merupakan tabungan instan pertama di Indonesia. Produk Shar-e Gold Debit Visa yang diluncurkan pada tahun 2011 tersebut mendapatkan penghargaan dari Museum Rekor Indonesia (MURI) sebagai Kartu Debit Syariah dengan teknologi chip pertama di Indonesia serta layanan e-channel seperti internet banking, mobile banking, ATM, dan cash management. Seluruh produk-produk tersebut menjadi pionir produk syariah di Indonesia dan menjadi tonggak sejarah penting di industri perbankan syariah.

Sejak tahun 2015, Bank Muamalat Indonesia bermetamorfosa untuk menjadi entitas yang semakin baik dan meraih pertumbuhan jangka panjang. Dengan strategi bisnis yang terarah Bank Muamalat Indonesia akan terus melaju mewujudkan visi menjadi "The Best Islamic Bank and Top 10 Bank in Indonesia with Strong Regional Presence”. (www.bankmuamalat.co.id)

Bank Muamalat Indonesia Malang didirikan pada tanggal 28 Agustus 2003. Kota Malang merupakan salah satu kota yang strategis untuk tempat pembukaan cabang baru di wilayah Jawa Timur, mengingat sebagaian besar penduduknya adalah umat muslim. Selain itu, kota Malang juga memiliki tingkat perputaran dana pada pihak ketiga yang relatif tinggi didukung dengan kegiatan perekonomian yang mengalami perkembangan dari tahun ke tahun. Bank Muamalat Cabang Malang tergabung dalam Regional VI bersama dengan Kantor Cabang Surabaya, Jember, Kediri, Denpasar, Kupang dan Mataram.

Kantor pusat Bank Muamalat Indonesia berlokasi di Gedung Arthaloka, Jl. Jendral Sudirman No. 2 Jakarta 10220, Indonesia, sedangkan Bank Muamalat Cabang Malang yang awalnya berlokasi di Jl. Kawi Atas No.36 A kini berada di Jl. Kertanegara No 02, Malang, tepatnya di Kecamatan Klojen kelurahan Kidul Dalem Kota Malang.

Lokasi Bank Muamalat Indonesia Malang sangat strategis karena berada sangat dekat dengan pusat kota yang memiliki fasilitas transportasi dan komunikasi yang cukup, sehingga keberadaan Bank Muamalat Indonesia mudah diketahui dan dikenal oleh masyarakat. Hal ini sangat berpengaruh dalam 
peningkatan pelayanan terhadap nasabah, sehingga pelayanan terhadap nasabah dapat terpuaskan. Berikut adalah sistem pengajuan Piutang Murabahah

$\begin{array}{lllll}\text { Customer } & \text { Unit Support } & \text { Operational } & \text { Operational } & \text { Relationship } \\ \text { Service } & \text { Pembiayaan } & \text { Manager } & \text { Pembiayaan } & \text { Manager } \\ & & & & \text { Remidial }\end{array}$

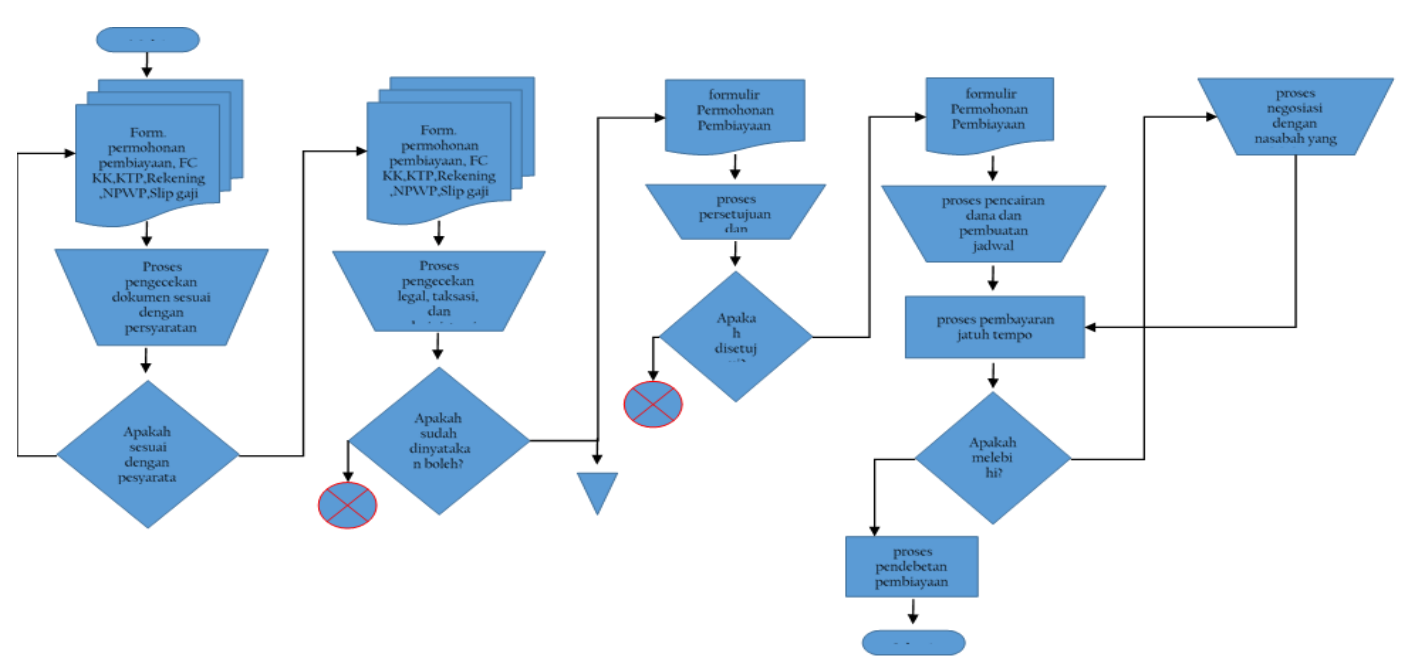

Gambar 1. Alur Pengajuan Piutang Murabahah PT. Bank Muamalat

Pengajuan piutang murabahah pada Bank Muamalat Malang yang dilakukan oleh nasabah yang tertarik untuk melakukan piutang dengan cara nasabah melakukan pengisian terhadap formulir yang sudah diberikan terlebih dahulu kepada nasabah dan telah memenuhi persyaratan seperti fotokopi KTP, KK, dan surat nikah (bila sudah menikah), Fotokopi NPWP, slip gaji dan surat keterangan bekerja, surat rekomendasi dari atasan kerja, dan fotokopi bukti legalitas agunan seperti sertifikat tanah dan BPKB .

Selanjutnya, data tersebut akan masuk ke SIMER yaitu system buatan Bank Muamalat yang kemudian data dari SIMER akan tersambung ke Bank Muamalat Surabaya guna mengecek kelengkapan dokumen. Bank Muamalat Surabaya telah membuat tim guna melakukan fungsi Ferifikator, yaitu memastikan nasabah bekerja, berpenghasilan, SILK dalam kondisi aman, dll. Apracial, menghitung jamianan yang diberikan dan melakukan survey ke lokasi guna melihat secara langsung serta Financing analisis, menghitung rasio yang diakuai untuk menentukan patform kepada nasabah.

Usulan pembiayaan akan dimintakan tandatangan ke region head, region $\mathrm{RFC}$, head of consumer financing setelah tim ferifikator, apracial dan financing analisis telah melakukan seluruh tugasnya. Ofering Latter atau persetujuan pembiayaan kepada nasabah akan turun kepada Bank Muamalat Malang dan diberikan kepada sales marketing yang bertanggungjawab kepada nasabah.

Ofering latter dari sales marketing akan diberikan kepada nasabah guna disetujui atau tidak.Nasabah yang sudah setuju maka Bank Muamalat Malang akan memanggil notaris untuk melihat jaminan guna dilakukan cheking dan validasi serta menyatakan jaminan tidak dalam sengketa, sertifikat ganda, dan menentukan nilai pajak jual beli.

Jaminan yang tidak memiliki masalah kemudian akan dilakukan akad yang disaksikan oleh nasabah, pasangan nasabah, notaris rekanan Bank dan legal dari Bank Muamalat. Akad yang sudah dilakukan oleh nasabah oleh sales 
marketing akan diberikan disburstmen atau pencairan dana kepada nasabah sejumlah platfom yang telah disepakati.

\section{Manajemen Risiko Piutang Murabahah pada Bank Muamalat Malang}

1. Penerapan Manajemen Risiko oleh Bank secara Efektif

Penerapan Manajemen Risiko oleh Bank secara efektif dengan mendasarkan pada pembentukan Komite Manajemen Risiko yang terdiri dari mayoritas Direksi dan Pejabat Eksekutif terkait guna melakukan pengawasan Risiko pada Bank. Selain dari pengawasan yang efektif dilakukan oleh Komite Manajemen Risiko, pengawasan aktif juga perlu dilakukan oleh Dewan Pengawas Syariah, Direksi dan Komisaris.

Dalam bagan struktur organisasi pada Bank Muamalat Malang memiliki fungsi manajemen risiko sendiri yang memiliki garis koordinasi dengan Branch Manager secara terpisah dengan fungsi lain dari struktur organisasi dan dibawah dari divisi terkait dengan fungsi lain. Memiliki komite manajemen risiko yang paling tidak terdiri dari mayoritas Direksi dan pejabat eksekutif terkait, yang ditetapkan Bank Muamalat sudah mendukung dilihat dari struktur organisasi Selain itu pada Bank Muamalat Malang juga memiliki garis koordinasi dengan bagian manajemen risiko.

Memiliki satuan kerja manajemen risiko pada struktur organisasi dalam Bank Muamalat Malang, dari gambar di jelaskan posisi dari manajemen risiko dan juga garis koordinasi pada setiap bagan. Manajemen risiko sendiri memiliki garis koordinasi langsung kepada Manajemen guna melakukan komunikasi langsung kepada pihak manager perihal risiko yang akan dihadapi. Pengawasan aktif oleh Direksi, dan Komisaris dilakukan setiap semester paling tidak satu kali. Pengawasan ini memang selalu rutin ada guna mengontrol kegiatan Bank agar berjalan dengan baik.

\section{Cakupan dari Manajemen Risiko}

Pada struktur organisasi di Bank Muamalat Malang memiliki satuan kerja manajemen risiko yang berdiri sendiri, yang digolongkan pada divisi terkait dan memiliki garis koordinasi kepada pihak manajemen guna memberikan informasi kepada pihak manajemen terkait temuan-temuan risiko utuk ditindak lanjut Pada Bank Muamalat juga memiliki pemisahan fungsi yang jelas pada setiap bagan yang ada pada struktur organisasi, dan juga pada setiap bagan memiliki penjelasan mengenai ranah kerja yang jelas pada setipa bagannya. Sehingga tidak akan terjadi tumpang tindih ranah kerja pada setiap fungsi dalam struktur organisasi yang di jelaskan pada Job Description.

Terkait piutang Murabahah terdapat 2 (dua) jenis transaksi yaitu KPR iB Muamalat dan iB Muamalat Multiguna pada Bank Muamalat Malang prosedur terdokumentasi dengan jelas, sehingga akan membuat kemungkinan terjadinya risiko pada saat melakukan transaksi akan menjadi kecil.

Prosedur pembiayaan Murabahah yang terdokumentasi dapat dilihat pada Flowchart pembiayaan, terlihat dengan jelas pengajuan hingga apabila terjadi permasalahan pada pembiayaan pada internal bank tidak mengalami permasalahan. Selain dari flowchart, struktur organisasi yang jelas juga perlu guna menjelaskan gambaran dari aktifitas bank secara keseluruhan. Gambar 
struktur organisasi menjelaskan hal tersebut dengan sangat jelas dan diperjelas lagi dengan alur komunikasi antar bagian sehingga dapat dinyatakan untuk struktur organisasi sudah memadai. Fungsi yang jelas pada setiap bagian dari struktur organisassi menggambarkan sebatas mana tanggung jawab dari bagian tersebut. Job description pada Bank Muamalat Malang sudah memadai dikarenakan memang telah ada penjelasan terkait setiap bagian pada gambar Struktur Organisasi.

Organisasi yang baik adalah organisasi yang memiliki arah gerak dan juga tujuan yang hendak dicapai oleh anggota dan juga oleh organisasi tersebut. Arah gerak dan juga tujuan dari suatu organisasi dapat dilihat dari visi dan misi, begitupun juga dengan Bank Muamalat Malang memiliki visi dan juga misi guna sebagai tujuan yang harus di capai dan langkah yang yang diambil oleh Bank Muamalat Malang.

\section{Peringkat Risiko}

Bank Muamalat Malang menetapkan batasan maksimum kepada nasabah yang akan melakukan piutang dengan akad murabahah baik itu menggunakan produk iB Muamalat Multiguna atau KPR iB Muamalat dengan batasan ini maka Bank dapat mengelola risiko dengan cara membuat PPAP yang nantinya akan diambil dari aktiva produktif Bank. Selain dengan adanya pengawasan yang dilakukan baik itu oleh Dewan Direksi, Dewan Pengawas Syariah, Komisaris, dan Komite Manajemen Risiko. Evaluasi juga diperlukan pada setiap prosedur guna sebagai cakupan dan juga menilai peringkat risiko dari perusahaan sebagai acuan penilaiannya baik itu prosedur lama atau prosedur baru.

Pengendalian atas risiko pada akad Murabahah di Bank Muamalat Malang sudah direncanakan dengan cukup baik terkait dengan pengajuan hingga pembayaran dari akad murabahah, sehingga apabila terjadi risiko dikemudian hari akan terjadi sudah dapat terantisipasi oleh pengendalian risiko yan sudaah dirancang.

Penentuan limit dan penetapan toleransi pada setiap transakisi diperlukan guna mengantisipasi agar pembiayaan tidak melebihi batas yang di tetapkan oleh Bank. Bank Muamalat telah menetapkan limit dan toleransi yang dapat dikeluarkan oleh Bank sudah memadai, dengan memisahkan masing-masing limit pada tiap produk yang menggunakan akad murabahah. Evaluasi secara berkala juga diperlukan, pada Bank Muamalat Malang kegiatan pelaporan yang dilakukan pihak Bank berupa SID selama 1 (satu) bulan kepada OJK guna dilakukan evaluasi dan pengawasan bulanan.

Konsekuensi atau risiko didapat dari aktifitas-aktifitas yang dilakukan tidak sesuai dengan yang diharapkan oleh prosedur yang telah di buat. Pengendalian atas suatu risiko dapat di antisipasi oleh Bank Muamalat dengan baik dilihat dari antisipasi tiap prosedur dan antisipasi tiap risiko yang timbul dari suatu aktifitas.

4. Pelaksanaan yang tidak bertentangan dengan Prinsip Syariah

Wewenang dan Tanggung Jawab Dewan Pengawas Syariah adalah mengevaluasi pertanggung jawaban Direksi atas pelaksanaan kebijakan Manajemen Risiko yang terkait dengan pemenuhan Prinsip Syariah. Dewan 
Pengawas Syariah melakukan pengawasan melalui pusat yang kemudian di terapkan kepada perusahaan anak. Prinsip Syariah yang diawasi oleh Dewan Pengawas Syariah tertuang pada Fatwa Dewan Syariah Nasional-Majelis Ulama Indonesia No. 111/DSN-MUI/IX/2017 mengenai Akad Jual Beli Murabahah. Pengawasan berkala oleh DPS.

Wewenang dan tugas dari dewan Pengawas Syariah adalah melakukan evaluasi atas kebijakan manajemen Risiko yang terkait dengan pemenuhan Prinsip Syariah. Pada Bank Muamalat pengawasan oleh Dewan Pengawas Syariah sendiri dilakukan di manajemen pusat dan regional guna melihat kebijakan bertransaksi yang diambil melanggar atau tidak dari prinsip syariah dapat dilihat dari persyaratan pengajuan pembiayaan yang sudah sesuai dengan Fatwa Dewan Syariah Nasional-Majelis Ulama Indonesia No. 111/DSNMUI/IX/2017 mengenai Akad Jual Beli Murabahah.

\section{Penerapan Manajemen Risiko pada Unit Usaaha Syariah}

Kewajiban pelaporan profil Risiko sebagaimana dimaksudkan untuk UUS mulai berlaku sejak laporan posisi bulan Juni 2012. Peraturan Bank Indonesia No 13/23/PBI/2011 disahkan dan Peraturan Bank Indonesia No 11/25/PBI/2009 tentang Perubahan atas Peraturan Bank Indonesia No 5/8/PBI/2003 tentang Peraturan Manajemen Risiko Bagi Bank Umum dinyatakan tidak berlaku bagi BUS dan UUS. Pada dasarnya Unit Usaha Syariah ialah Unit yang berjalan dengan prinsip syariah dengan perusahaan induk adalah perusahaan konvensional, Bank Muamalat adalah Bank Unit Syariah yang pada dasarnya adalah perusahaan dengan prinsip syariah.

Pada Bank Muamalat sendiri tidak memiliki Unit Usaha Syariah dikarenakan Bank Muamalat termasuk Bank Umum Syariah. Bank Umum Syariah sudah tidak memerlukan Unit Usaha Syariah yang membantu mengurusi kegiatan syariah, dikarenakan Bank Umum Syariah sudah menerapkan system syraiah pada kegiatan utama, sedang Unit Usaha Syariah masih menggunakan secara konvensional dalam kegiatan utamanya. Penerapan Manajemen Risiko pada Unit Usaha Syariah pada Bank Muamalat Malang tidak ada.

\section{Penyampaian Triwulan kepada BI}

Bank Indonesia menerima laporan menegenai kondisi dari bank setiap quartal atau setiap 3 (tiga) bulan 1 (satu) kali di akhir quartal pada bulan Maret, Juni, September, dan Desember dengan batasan waktu yang sudah di tentukan oleh Bank Indonesia yaitu paling lambat 15 (lima belas) hari kerja setelah akhir bulan. Pelaporan dilakukan oleh bagian opersional setiap tanggal 31 atau 30 kepada BI yang kemudian akan dipublikasikan 2 minggu setelah pelaporan.

Kesesuaian format pelaporan kepada Bank Indonesia paling tidak mencakupi pelaporan, yang sama dengan pelaporan kepada Manajemen. Pelaporan yang sama dengan yang dilaporkan ke pihak manajemen, untuk dilaporkan kembali kepada Bank Indonesia. Format pelaporan yang dilaporkan triwulan oleh Bank akan dipublikasikan. Pelaporan yang dilakukan oleh Bank Muamalat kepada Bank Indonesia tentang laporan keuangan selalu dilaporakan triwulan guna dipublikasikan agar debitur mengetahui keuangan dari Bank. Laporan keuangan Bank muamalat dilaporkan selalu tepat waktu dan pada 
minggu ke 2 (dua) setelah akhir bulan akan langsung di publikasikan di website resmi BI.

Profil risiko perusahaan dilaporkan guna mengamankan Aset nasabah yang dititipkan kepada Bank untuk dievaluasi oleh Bank Indonesia. Penyampaian profile risiko selalu dilaporkan oleh bagian operasional setiap akhir bulan guna melihat transaksi apa saja yang telah dilakukan baik itu nasabah atau Bank, pada Bnak Muamalat malang pelaporan profile risiko berupa SID atau SILK dilaporkan kepada OJK per 1 Januari 2018.

\section{Pembahasan}

Pemaparan mengenai pengendalian atas risiko-risiko yang ada pada pembiayaan murabahah pada Bank Muamalat Malang telah memadai, dikarenakan selain dari pengendalian untuk kegiatan yang berkaitan dengan akad murabahah Bank telah memadai terhadap regulasi Bank Indonesia terkait pengendalian atas risiko yang telah diatur oleh Peraturan Bank Indonesia No 13/23/PBI/2011. Dalam pelaksanaanya, Bank Muamalat Malang sudah cukup baik menerapkan manajemen risiko berdasarkan regulasi dari BI dan juga kebijakan yang diambil terkait pengendalian risiko pada kegiatan dengan akad Murabahah. Penerapan Manajemen Risiko oleh Bank secara Efektif dapa dilihat dari kepemilikan komite tersendiri yang ada pada struktur organisasi perusahaan serta hasil wawancara yang menyatakan adanya pengawasan yang selalu dilakukan oleh Direksi dan Komisaris.

Bank juga memiliki cakupan dari Manajemen risiko yang memadai yang terdiri dari visi dan misi organisasi pada Job description, struktur organisasi dan prosedur pembiayaan yang terdokumentasi Peringkat risiko yang ada pada bank juga sudah memadai didukung dari hasil wawancara kepada pihak Bank yang menyatakan adanya penetapan limit, evaluasi secara berkala yang dilakukan oleh OJK dengan menyerahkan SID dan pengendalian atas risiko yang terjadi pada piutang murabahah.

Pelaksanaan transaksi yang sesuai dengan prinsip-prinsip syariah yang sesuai dengan fatwa MUI No 111/DSN-MUI/Ix/2017 yang sesuai dengan form pengajuan pembiayaan yang ada pada Bank. Penyampaian profil risiko yang dilakukan kepada BI sesuai hasil wawancara kepada pihak Bank dilakukan pelaporan pada minggu ke 2 setelah akhir triwulan.

Pengendalian risiko yang dilakukan oleh Bank untuk transaksi murabahah sudah baik dari seperti halnya membuat Pencadangan Penghapusan Aktiva Produktif (PPAP), melakukan analisa 5C yaitu Caracter berkaitan dengan kepribadian dari nasabah, Capital terkait dengan kondisi keuangan dari nasabah, Capacity berkaitan dengan pengelolaan keuangan dari nasabah, Conditional of economy terkait dari kondisi ekonomi di luar dari nasabah dan bank, dan Colateral terkait dengan barang jaminan dari nasabah. Bank juga menerapkan prosdur apabila nasabah melakukan keterlambatan dengan cara diingatkan selama 3 hari berturut-turut oleh Bank, penunggakan akan diantisipasi dengan cara melakukan $3 \mathrm{R}$ kepada nasabah (Rekonditioning yaitu perubahan sebagian atau seluruh syarat-syarat kredit yang tidak terbatas pada perubahan jadwal pembayaran, jangka waktu, dan persyaratan lainya sepanjang tidak menyangkut perubahan maksimal saldo kredit, Reschedule yaitu perubahan persayratan kredit 
yang hanya menyangkut jadwal pembayaran dan jangka waktu kredit, Restrukture yaitu perubahan syarat-syarat kredit yang menyangkut penambahan dana bank, konversi seluruh atau sebagian tunggakan bunga menjadi pokok kredit baru atau konversi seluruh atau sebagian dari kredit menjadi penyertaan dalam perusahaan, yang dapat disertakan dengan penjadwalan kembali atau persyaratan kembali), dan apabila tidak bisa melunasi tunggakan, Bank akan memberikan opsi untuk melelang barang atau Bank yang akan melakukan lelang.

\section{SIMPULAN}

Berdasarkan hasil analisis, Penerapan Manajemen Risiko oleh Bank Muamalat Malang sudah efektif. Keefektifan tersebut dapat dilihat dari kepemilikan komite tersendiri yang ada pada struktur organisasi Bank, serta adanya pengawasan yang dilakukan oleh Direksi dan Komisaris.

Bank juga memiliki cakupan dari Manajemen risiko yang memadahi yang terdiri dari visi dan misi organisasi, Job description, struktur organisasi dan prosedur pembiayaan yang terdokumentasi. Selain itu adanya peringkat risiko yang ada pada bank juga sudah memadahi didukung dari adanya penetapan limit, evaluasi secara berkala yang dilakukan oleh OJK dengan menyerahkan SID dan pengendalian atas risiko yang terjadi pada piutang murabahah.

Pelaksanaan transaksi yang sesuai dengan prinsip-prinsip syariah yang sesuai dengan fatwa MUI No 111/DSN-MUI/Ix/2017 yang sesuai dengan form pengajuan pembiayaan yang ada pada Bank. Penyampaian profil risiko yang dilakukan kepada BI sesuai dengan hasil kepada pihak Bank dilakukan pelaporan pada minggu ke 2 setelah akhir triwulan.

Pengendalian risiko yang dilakukan oleh Bank untuk transaksi murabahah sudah memadai, seperti halnya Bank diharuskan membuat dan melaksanakan Pencadangan Penghapusan Aktiva Produktif (PPAP), melakukan analisa 5C (Caracter, Capital, Capacity, Conditional of economy, dan Colateral), Bank juga menerapkan prosdur, apabila nasabah melakukan keterlambatan pembayaran dengan cara diingatkan selama 3 hari tidak ditanggapi, Bank akan mengantisipasi dengan cara melakukan 3R (Rekonditioning, Reschedule, dan Restrukture) kepada nasabah dan apabila tidak bisa melunasi tunggakan, Bank akan memberikan opsi untuk melelang barang atau Bank yang akan melakukan lelang.

\section{DAFTAR PUSTAKA}

Antonio, Muhammad Syafi'I. 2005. Bank Syariah, Dari Teori ke Praktek, Gema Insni Press: Jakarta.

Bank Indonesia. 2003. Surat Edaran Bank Indonesia No. 5/21/DPNP tahun 2003 perihal Penerapan Manajemen Risiko bagi Bank.

Bank Indonesia. 2003. Surat Edaran Bank Indonesia No. 5/22/DPNP tahun 2003 perihal Pedoman Sistem Pengendalian Internal bagi Bank.

Fariada, Arifa K. 2015. "Penerapan Audit berbasis Risiko pada Pembiayaan Murabahah"

Hakim, lukman. 2012, Prinsip-Prinsip Ekonomi Islam, Yogyakarta: Erlangga, 2012, hlm.116-117 
Hasanah, N.,Puspitasari, N. dan Farida, L. 2015. Risiko Akad Murabahah Serta Pengelolaan Risiko Akad Murabahah Pada BMT-UGT Sidogiri Cabang Wongsorejo, Kabupaten Banyuwangi. E-Journal Ekonomi Bisnis dan Akuntansi, 2015, Volume 2 (1). 1-5.

Otoritas Jasa Keuangan-OJK. 2017. "Statistik Perbankan Syariah" https://www.ojk.go.id/id/kanal/syariah/data-dan-statistik/statistikperbankan-syariah/Default.aspx [diakses pada 28 Februari 2018]

PT Bank Muamalat Tbk. 2016. "Macam-macam pembiayaan pada Bank Muamalat"http://www.bankmuamalat.co.id/pembiayaancorporate/pembia yaan-ib-muamalat-modal-kerja [diakses pada 22 Februari 2018]

Peraturan Bank Indonesia . 2011. Nomor 13/23/PBI/2011. Manajemen Risiko Pada Perbankan

Peraturan Republik Indonesia . 2008. Undang-undang nomor 21 tahun 2008 Bab 1, Pasal 1,ayat 7 , hal.3

Sanusi, Anwar. 2011,Metodologi Penelitian Bisnis,Jakarta,Salemba Empath hal.13

Sawyer, L. B., Dittenhofer, M. A. dan Scheiner, J. H. (2005). Sawyer's Internal Auditing. Jakarta: Salemba Empat.

Singgih, R.,Eriyanto. dan Daryanto, H.K. 2012. Kajian Sistem Pengendalian Risiko Kredit dalam Pelaksanaan Audit Berbasis Risiko (kasus pada Kantor Cabang Bank). Jurnal Manajemen \& Agribisnis, Vol. 9 No. 1 Maret 2012.

Sri, Fanny Y. 2013. Akad Pembiayaan Murabahah dan Praktiknya pada PT Bank Syariah Mandiri Cabang Manado. Jurnal Lex Privatum, vol.I/No.2/AprJun/2013.

Ulum , I dan A. Juanda. 2016 “ Metodologi Penelitian Akuntansi Klinik Sekripsi Edisi 2. Malang : Aditya Media Publishing.

Wandayanik, Riris .2015. Implementasi Manajemen Risiko Pembiayaan Murabahah di Bank BNI Syariah Kantor Cabang Pembantu Mojokerto. ElQist, Vol. 05, April 2015.

Wiroso, 2005. Jual Beli Murabahah. Yogyakarta : UII pres e-Journal 